\title{
FORMULASI SEDIAAN KRIM EKSTRAK ETANOL DAUN BELIMBING WULUH (Averrhoa bilimbi L.) DENGAN BASIS ASAM STEARAT
}

\section{FORMULATION OF CREAM ETHANOL EXTRACT OF BELIMBING WULUH LEAF (Averrhoa bilimbi L.) WITH STEARIC ACID BASE}

\author{
Rahmawati Azizah Istiqomah ${ }^{1}$, Fara Azzahra ${ }^{1}$ \\ ${ }^{1}$ Program Studi Diploma III Farmasi Akademi Farmasi Indonesia Yogyakarta \\ Korespondensi: faraazzahra@afi.ac.id
}

\begin{abstract}
ABSTRAK
Daun belimbing wuluh mengandung flavoniod, saponin, tanin, sulfur, peroksidase. Ekstrak etanol daun belimbing wuluh diformulasikan menjadi sediaan krim. Tujuan penelitian ini adalah mengetahui karakteristik fisik krim ekstrak etanol daun belimbing wuluh.

Penelitian ini merupakan eksperimental dengan metode posttest only control group design. Ekstrak hasil maserasi diformulasikan menjadi krim menggunakan basis asam stearat. Krim dibuat menjadi FI formula kontrol (basis krim) dan FII krim dengan ekstrak etanol daun belimbing wuluh. Krim diuji organoleptis, $\mathrm{pH}$, homogenitas, dan daya sebar. Hasil uji $\mathrm{pH}$ dan uji daya sebar diuji normalitas menggunakan Shapiro Wilk. Perbedaan karakteristik FI dan FII diuji menggunakan Independent sample Ttest.

Hasil penelitian menunjukkan ada perbedaan ekstrak etanol daun belimbing wuluh terhadap organoleptis dan $\mathrm{pH}$ krim. Warna FII hijau kecoklatan sedangkan warna FI putih. Hasil pH FII 5,66 $\pm 0,10$ dan FI 6,5 \pm 0,15, hasil uji Independent T-test $\mathrm{pH}$ krim menunjukkan hasil $(\mathrm{Sig}<0,05)$, ini berarti terdapat perbedaan signifikan antara nilai pH FI dan FII.Hasil uji daya sebar dan homogenitas tidak memiliki perbedaan signifikan antara FI dan FII. Rerata daya sebar FI 6,41 $\pm 0,35 \mathrm{~cm}$ dan rerata daya sebar FII 6,77 \pm $0,11 \mathrm{~cm}$. FI dan FII menunjukkan sediaan krim yang homogen.

Kesimpulan penelitian yaitu ekstrak etanol daun belimbing wuluh dengan basis asam stearat dapat dibuat dalam sediaan krim dan memiliki sifat fisik yang baik sesuai standar persyaratan sediaan krim.
\end{abstract}

Kata kunci: Ekstrak etanol daun belimbing wuluh, krim, asam stearat, uji fisik

\begin{abstract}
Belimbing wuluh leaf contain flavonoids, saponins, tannins, sulfur, peroxidase. The ethanol extract of belimbing wuluh leaf is formulated into a cream preparation. The purpose of this study was to determine the physical characteristics of the ethanol extract cream of belimbing wuluh leaves.

This research is an experimental study with a posttest only control group design methodology. The macerated extract was formulated into a cream using a stearic acid base. The cream was made into FI control formula (cream base) and cream FII with ethanol extract of belimbing wuluh leaves. The cream was tested for organoleptic, $\mathrm{pH}$, homogeneity, and dispersibility. Data from $\mathrm{pH}$ value test and spreadability test were analyzed using SPSS, normality test using Shapiro Wilk. Differences in FI and FII characteristics were tested using the Independent sample T-test.

The results showed that there was an effect of the ethanol extract of belimbing wuluh leaves on organoleptic and cream pH. The FII color is brownish green while the FI color is white. The results of pH FII $5.66 \pm 0.10$ and FI $6.5 \pm 0.15$, the results of the Independent T-test $\mathrm{pH}$ cream showed results $(\mathrm{Sig}<0.05)$, this means that there is a significant difference between the FI and FII pH values. The results of the spreadability and homogeneity tests did not have a significant difference between FI and FII. The average FI spreadability was $6.41 \pm 0.35 \mathrm{~cm}$ and the average FII spreadability was $6.77 \pm 0.11 \mathrm{~cm}$. FI and FII formula of cream is show homogeneous results.

The conclusion of this research is that the ethanol extract of belimbing wuluh leaf with stearic acid base can be made in cream formulations and has good physical properties accroding to the standart requirements.
\end{abstract}

Keywords: Ethanol extract of belimbing wuluh leaf, cream, stearic acid, physical test 


\section{PENDAHULUAN}

Belimbing wuluh (Averrhoa bilimbi L.) merupakan salah satu tanaman yang dapat digunakan untuk mengobati jerawat. Hampir seluruh bagian dari tanaman belimbing wuluh dapat dimanfaatkan, salah satunya bagian daun. Daun belimbing wuluh memiliki kandungan flavonoid, saponin, tanin, sulfur, asam format, peroksidase, kalsium oksalat, dan kalium sitrat (Dalimartha, 2008) Penggunaan ekstrak etanol daun belimbing wuluh secara langsung dinilai kurang efisien, sehingga perlu dikembangkan dalam suatu sediaan farmasi untuk mempermudah penggunaannya

Ekstrak etanol daun belimbing wuluh dapat dikembangkan menjadi bentuk sediaan farmasi, salah satunya adalah sediaan krim. Krim dapat memberikan efek dingin, mengkilap, dan melembabkan kulit (Anwar, 2012). Penggunaan bahan pengemulsi dalam sediaan krim sangat menentukan sifat fisik dan stabilitas sediaan krim, penggunaan asam stearat sebagai emulgator akan membentuk basis yang kental dan tingkat kekentalan tersebut ditentukan oleh jumlah trietanolamin (TEA)yang digunakan (Rowe dkk, 2009).

Penelitian yang dilakukan Putri (2013) krim dengan basis asam stearat mempunyai daya sebar lebih baik dibandingkan krim dengan basis cera alba. Sediaan farmasi, salah satunya adalah krim harus memenuhi uji persyaratan sifat fisik krim, antara lain uji homogenitas, uji organoleptis, uji $\mathrm{pH}$, dan uji daya sebar. Pengujian ini bertujuan untuk memastikan bahwa krim aman digunakan karena telah memenuhi persyaratan uji fisik krim (Rosmala dkk., 2014)

Berdasarkan uraian diatas, perlu dilakukan formulasi krim dari ekstrak etanol daun belimbing wuluh dengan basis asam stearat dan pengujian karakteristik fisik yang meliputi uji homogenitas, uji $\mathrm{pH}$, uji organoleptis, serta uji daya sebar.

\section{METODE PENELITIAN}

\section{Bahan}

Pada penelitian ini bahan yang digunakan adalah daun belimbing wuluh (Averhoa bilimbi L.) yang diperoleh dari Bantul, Yogyakarta, etanol 96\% grade A (CV. General Labora), TEA (MKR Chemical), asam stearat (Brataco Chemical), setil alkohol (Brataco Chemical), adeps lanae (Brataco chemical), gliserin (Brataco Chemical), metil paraben (Brataco Chemical), propil paraben (Brataco Chemical) dan aquadest (CV. General Labora).

\section{Alat}

Alat yang digunakan pada penelitian ini antara lain mortir, stamfer, timbangan digital (Acis), sendok tanduk, sendok stainless, spatula, sudip, penjepit kayu, oven (Memmert), gelas ukur (Iwaki), erlenmeyer (Duran), corong kaca (Herma), gelas beaker (Iwaki), cawan penguap, kertas saring, $\mathrm{pH}$ meter (Lutron PH208), mikroskop, plat kaca, waterbath (Memmert), dan rotary vacum evaporator (Heidolp).

\section{Prosedur Penelitian}

\section{Determinasi Daun Belimbing Wuluh}

Determinasi daun belimbing wuluh dilakukan di Laboratorium Biologi Fakultas MIPA Universitas Ahmad Dahlan Yogyakarta.

\section{Pembuatan Ekstrak Etanol Daun Belimbing Wuluh}

Pembuatan ekstrak etanol daun belimbing wuluh diawali dengan melakukan sortasi basah terhadap daun belimbing wuluh yang telah terkumpul, dicuci bersih menggunakan air mengalir lalu dipotong-potong kecil. Setelah itu dikeringkan menggunakan oven pada suhu $50^{\circ} \mathrm{C}$ selama 48 jam. Daun yang telah kering kemudian diblender dan diayak menggunakan ayakan ukuran 60 mesh (Hasim dkk., 2019).

Maserasi dilakukan dengan menggunakan perbandingan serbuk ekstrak daun belimbing wuluh dengan etanol 96\% sebanyak $1: 5$. Serbuk daun belimbing wuluh sebanyak $800 \mathrm{~g}$ dimasukan kedalam bejana dan ditambahkan pelarut etanol 96\% dengan volume $4 \mathrm{~L}$, selanjutnya dilakukan pengadukan selama 3 jam, lalu ditutup menggunakan alumunium foil dan didiamkan selama 24 jam, diletakkan ditempat yang terhindar dari sinar matahari secara langsung, kemudian maserat dikeluarkan dan disaring dengan kertas saring untuk memisahkan filtrat (1) dengan residu. Proses ini dilakukan berulang dengan 2 kali penggantian pelarut pada residu hasil penyaringan. Filtrat (1 dan 2) digabungkan dan diuapkan menggunakan Rotary Evaporator dengan suhu $50^{\circ} \mathrm{C}$, kemudian untuk mendapat ekstrak kental dilakukan penguapan menggunakan waterbath dengan suhu $50^{\circ} \mathrm{C}$ (Meila dkk., 2017 dan Insani dkk., 2016). 


\section{Pembuatan Krim Ekstrak Etanol Daun Belimbing Wuluh}

Pembuatan krim ekstrak etanol daun belimbing wuluh menggunakan metode peleburan. Krim ini terdiri dari dua fase, yaitu fase minyak (asam stearat, adeps lanae, setil alkohol, parafin cair, dan propil paraben) dan fase air (TEA, gliserin, metil paraben, dan aquadest). Langkah awal adalah meleburkan fase minyak pada suhu $70^{\circ} \mathrm{C}$ menggunakan waterbath, fase air dilarutkan dengan cara dileburkan pada suhu $70^{\circ} \mathrm{C}$ (Rabima dan Marshali., 2017).

Setelah fase minyak terlebur, selanjutnya masukkan fase air sedikit demi sedikit dimasukkan kedalam fase minyak sambil aduk hingga homogen, kemudian tuangkan campuran tersebut kedalam mortir panas, dan aduk secara konstan hingga terbentuk masa krim. Ekstrak kental etanol daun belimbing wuluh yang telah diencerkan menggunkan etanol 96\% dituang kedalam mortir panas, lalu digerus hingga tidak ada gumpalan, selanjutnya masukkan basis krim sedikit demi sedikit kedalam ekstrak dan aduk konstan hingga homogen (Rabima dan Marshali, 2017). Formula Krimdapat dilihat pada tabel I.

Tabel I. Formula Krim Ekstrak Etanol Daun Belimbing Wuluh Dengan Basis Asam Stearat

\begin{tabular}{lccl}
\hline \multicolumn{1}{c}{ Komponen } & FI & FII & \multicolumn{1}{c}{ Kegunaan } \\
\hline Ekstrak Etanol Daun Belimbing Wuluh $(\mathrm{g})$ & - & 1,25 & Zat aktif \\
TEA $(\mathrm{mL})$ & 0,5 & 0,5 & Emulgator \\
Asam Stearat $(\mathrm{g})$ & 5 & 5 & Basis, emulgator \\
Adeps Lanae $(\mathrm{g})$ & 2 & 2 & Basis, emollient \\
Setil Alkohol $(\mathrm{g})$ & 1,5 & 1,5 & Emolient \\
Gliserin $(\mathrm{mL})$ & 7,5 & 7,5 & Emolient, humektan \\
Metil Paraben $(\mathrm{g})$ & 0,025 & 0,025 & Pengawet \\
Propil Paraben $(\mathrm{g})$ & 0,05 & 0,05 & Pengawet \\
Etanol 96\% & $\mathrm{qs}$ & $\mathrm{qs}$ & Pelarut Ekstrak \\
Paraffin Cair $(\mathrm{mL})$ & 2 & 2 & BahanTambahan \\
Aquadest $(\mathrm{g})$ ad & 50 & 50 & Pelarut \\
\hline
\end{tabular}

Keterangan :

FI : Formula kontrol (tanpa ekstrak etanol daun belimbing wuluh)

FII : Formula dengan penambahan ekstrak etanol daun belimbing wuluh

\section{Pengujian Sifat Fisik Sediaan Krim Ekstrak Etanol Daun Belimbing Wuluh Uji Organoleptis}

Uji organoleptis dilakukan dengan melihat tampilan fisik krim ekstrak etanol daun belimbing wuluh yang meliputi warna, bentuk, bau yang sama dan dapat dikatakan memenuhi uji organoleptis. Uji ini dilakukan dengan melihat pemisahan fase, perubahan warna, dan perunahan bau tengik (Elya dkk., 2013).

\section{Uji Homogenitas}

Uji homogenitas dilakukan dengan cara mengoleskan krim ekstrak etanol daun belimbing wuluh pada kaca objek, lalu diamati dibawah mikroskop. Krim dikatakan homogen apabila krim memiliki bau yang merata,warna yang merata, tidak ada butiran-butiran halus, serta terlihat homogen saat dilihat menggunakan mikroskop (Elya dkk., 2013).

\section{Uji pH}

Uji $\mathrm{pH}$ dilakukan dengan cara mengukur nilai $\mathrm{pH}$ menggunakan $\mathrm{pH}$ meter. Pengujian $\mathrm{pH}$ dilakukan dengan cara dimana elektroda dicelupkan kedalam krim esktrak etanol daun belimbing wuluh yang telah diencerkan dengan air (perbandingan 1:10), lalu angka $\mathrm{pH}$ meter dibiarkan bergerak sampai menunjukkan angka tetap (Akhtar dkk., 2011).

\section{Uji Daya Sebar}

Krim ekstrak etanol daun belimbing wuluh ditimbang sebanyak 0,5 g kemudian diletakan ditengah cawan berskala, kemudian tutup dengan kaca sebagai beban awal, diamkan selama 1 menit lalu dicatat diameter sebarnya. Selanjutnya ditambahkan $50 \mathrm{~g}$ beban, diamkan selama 1 menit dan dicatat diameter sebarnya. Lakukan pengukuran yang sama setiap penambahan $50 \mathrm{~g}$ beban sampai beban mencapai $250 \mathrm{~g}$ (Ulaen dkk., 2012). 


\section{HASIL DAN PEMBAHASAN}

\section{Determinasi Daun Belimbing Wuluh}

Determinasi daun belimbing wuluh yang diperoleh dari Bantul, Yogyakarta dilakukan di Laboratorium Biologi Universitas Ahmad Dahlan Yogyakarta, berdasarkan hasil determinasi dapat disimpulkan bahwa daun yang digunakan dalam penelitian adalah spesies Averrhoa bilimbi $\mathrm{L}$ dan famili Oxalidaceae.

\section{Ekstraksi Daun Belimbing Wuluh}

Ekstraksi daun belimbing wuluh menggunakan metode maserasi. Metode maserasi dipilih karena memiliki keuntungan antara lain cara yang mudah dilakukan, tidak memerlukan proses pemanasan secara langsung, sehingga komponen senyawa daun belimbing wuluh yang tidak tahan pemanasan dapat tetap terjaga (Parmadi, 2016). Serbuk daun belimbing wuluh yang telah diayak dengan ayakan ukuran 60 mesh sebanyak 800 gram diekstraksi menggunakan cairan penyari etanol 96\% sebanyak 4 L selama 1 hari, kemudiam disaring. Residu hasil penyaringan diremaserasi menggunakan cairan penyari etanol 96\% sebanyak 4 L. Selanjutnya maserat diuapkan menggunakan Rotary Evaporator, untuk mendapat ekstrak kental dilakukan penguapan diatas waterbath. Ekstrak kental yang diperoleh sebanyak 129,03 gram dengan rendemen sebesar $16,12 \%$.

\section{Pengujian Sifat Fisik Krim Ekstrak Etanol Daun Belimbing Wuluh}

\section{Uji Organoleptis}

Pengujian organoleptis dilakukan secara visual dengan mengamati warna, bau, serta bentuk sediaan krim. Hasil uji organoleptis dapat dilihat pada tabel II.

Tabel II. Hasil Uji Organoleptis Krim Ekstrak Etanol Daun Belimbing Wuluh

\begin{tabular}{lll}
\hline \multicolumn{1}{c}{ Pengamatan } & \multicolumn{1}{c}{ FI } & \multicolumn{1}{c}{ FII } \\
\hline Warna & Putih & Hijau kecoklatan \\
Bau & Tidak berbau & Bau khas ekstrak etanol daun belimbing wuluh \\
Bentuk & Semi padat & Semi padat \\
\hline
\end{tabular}

Keterangan:

FI : Formula krim tanpa ekstrak etanol daun belimbing wuluh

FII : Formula krim ekstrak etanol daun belimbing wuluh

Hasil pengamatan organoleptis berdasarkan tabel II pada krim kontrol (FI) dan krim esktrak etanol daun belimbing wuluh (FII) menunjukkan perbedaan pada warna dan bau krim. FI menghasilkan krim berwarna putih dan tidak berbau, sedangkan pada FII menghasilkan krim berwarna hijau kecoklatan dan bau khas esktrak etanol daun belimbing wuluh, perbedaan ini disebabkan adanya penambahan ekstrak kental daun beleimbing yang menyebabkan warna dan bau krim.

\section{Uji Homogenitas}

Uji homogenitas bertujuan untuk mengetahui komponen dalam sediaan krim sudah tersebar secara merata atau belum, pengujian dilakukan dengan cara mengoleskan sebagian krim pada kaca objek, lalu diamati dibawah mikroskop dengan perbesaran 100 kali. Hasil uji homogenitas dapat dilihat pada gambar I.

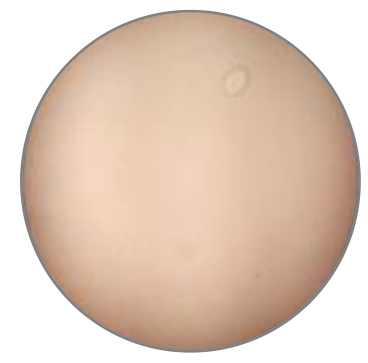

F1

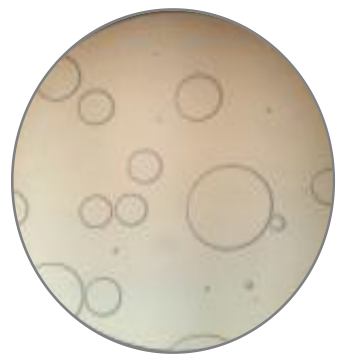

F2

Gambar 1. Hasil Uji Homogenitas Krim F1 (Formula krim tanpa ekstrak etanol daun belimbing wuluh) dan F2 (Formula krim ekstrak etanol daun belimbing wuluh) 
Hasil uji homogenitas berdasarkan gambar 1 pada krim FI dan FII menunjukkan hasil yang homogen, krim dikatakan homogen apabila tidak terdapat butiran-butiran halus, memiliki warna yang merata dan tidak terdapat bercak hitam saat diamati dibawah mikroskop (Sugiyono dkk., 2012). Hasil pengujian pada FII tetap menghasilkan krim yang homogen, hal ini dikarenakan ekstrak etanol daun belimbing larut dalam etanool 96\% dan mudah bercampur dengan basis krim.

\section{Uji pH}

Uji pH bertujuan untuk mengetahui keamanan krim saat digunakan, apabila terdapat ketidaksesuaian dengan $\mathrm{pH}$ kulit maka dapat menyebabkan iritasi, kulit kering, dan rasa tidak nyaman saat digunakan (Ismarani dkk., 2014). Hasil pengujian pH dapat dilihat pada tabel III.

Tabel III. Hasil Uji pH Krim Ekstrak Etanol Daun Belimbing Wuluh

\begin{tabular}{cc}
\hline & Rerata Nilai pH \\
\cline { 2 - 2 } Formula & $\overline{\boldsymbol{x}} \pm \boldsymbol{S D}$ \\
\hline FI & $6,56 \pm 0,15^{*}$ \\
FII & $5,66 \pm 0,10^{*}$ \\
\hline
\end{tabular}

Keterangan:

* : Terdapat perbedaan signifikan $(\mathrm{Sig}<0,05)$

Krim FI dan FII masing-masing dibuat sebanyak 3 replikasi, hasil peengujian berdasarkan tabel III menunjukkan rerata nilai $\mathrm{pH}$ sediaan krim FI dan FII secara berturut-turut yaitu 6,56 $\pm 0,15$ dan 5,66 $\pm 0,10$. Nilai $\mathrm{pH}$ sediaan krim harus sesuai dengan $\mathrm{pH}$ wajah, rentang nilai $\mathrm{pH}$ wajah yaitu sebesar 4,5-6,5 (Djajadisastra, 2004). Hal ini menunjukkan bahwa hasil penelitian FI memenuhi persyaratan pH kulit, dan FII memiliki nilai $\mathrm{pH}$ diambang batas persyaratan, namun $\mathrm{pH}$ FII masih dapat diterima karena menurut Faradiba dkk. (2013) rentang $\mathrm{pH}$ kulit adalah 4,0 - 7,5.

Hasil analisis statistik Independent T-test menunjukkan bahwa terdapat perbedaan bermakna pH antara FI dan FII dengan nilai signifikan $0,01 \quad($ sig $<0,05)$. Penambahan ekstrak etanol daun belimbing wuluh menurunkan nilai $\mathrm{pH}$ krim. Hal ini dipengaruhi karena ekstrak etanol daun belimbing wuluh memiliki $\mathrm{pH}$ yang asam yaitu sebesar 5,58. Hasil $\mathrm{pH}$ ekstrak ini tidak jauh berbeda dengan penelitian yang dilakukan oleh Sitinjak (2018) yang menyatakan bahwa nilai $\mathrm{pH}$ ekstrak etanol daun belimbing wuluh sebesar 5,90 dan penambahan ekstrak etanol daun belimbing wuluh dalam sediaan dapat menurunkan nilai $\mathrm{pH}$.

\section{Uji Daya Sebar}

Pengujian daya sebar dilakukan dengan tujuan untuk mengetahui kemampuan krim dalam penyebaran merata saat penggunaan (Ardini dan Pudji, 2019). Uji daya sebar dilakukan 3 kali replikasi, hasil pengujiannya dapat dilihat pada tabel IV.

Tabel IV. Hasil Uji Daya Sebar Krim Ekstrak Etanol Daun Belimbing Wuluh

\begin{tabular}{|c|c|c|}
\hline \multirow[b]{2}{*}{ Formula } & Rerata Daya Sebar & \multirow{2}{*}{$P$ value } \\
\hline & $\bar{x} \pm S D(\mathbf{c m})$ & \\
\hline $\begin{array}{l}\text { FI } \\
\text { FII }\end{array}$ & $\begin{array}{l}6,41 \pm 0,35 \\
6,37 \pm 0,11\end{array}$ & 0,860 \\
\hline
\end{tabular}

Rata-rata daya sebar FI dan FII secara berturut-turut adalah $6,41 \pm 0,35 \mathrm{~cm}$ dan $6,37 \pm 0,11 \mathrm{~cm}$. Formula II memiliki daya sebar yang lebih kecil dibandingkan Formula I, namun kedua Formula tersebut memenuhi syarat daya sebar krim, dimana syarat diameter daya sebar krim sebesar 5-7 cm (Garg dkk., 2002).

Hasil pengujian daya sebar krim selanjutnya dianalisis menggunakan uji Independent T-test untuk mengetahui perbedaan daya sebar antara FI dan FII. hasil analisis menunjukkan nilai signifikan lebih dari 0,05 (Sig $>0,05)$. Hal ini menunjukkan bahwa tidak ada perbedaan bermakna antara daya sebar FI dan FII.

\section{KESIMPULAN}

Sediaan krim ekstrak etanol daun belimbing wuluh dengan basis asam stearat memenuhi persyaratan uji karakteristik fisik meliputi organoleptis, homogenitas, $\mathrm{pH}$, dan daya sebar. 


\section{DAFTAR PUSTAKA}

Akhtar, N., B. A. Khan, M. S. Khan, T. Mahmood, H. M. S. Khan, M. Iqbal and S. Bashir., 2011. Formulation Development and Moisturising Effect of a Topical Cream of Aloe vera Extract. World Academy of Science, Engineering and Technology 75 : University of Bahawalpur Pakistan

Anwar., 2012. Eksipien Dalam Sediaan Farmasi Karakterisasi dan Aplikasi. Jakarta: Penerbit Dian Rakyat.

Ardini, D., dan Pudji, R., 2019. Studi Variasi Gelling Agent PVA (Propil Vinil Alkohol) pada Formulasi Masker Peel-of Ekstrak Lidah Buaya (Alove vera) sebagai Anti Jerawat. Jurnal Kesehatan.10 (2): 245-251.

Dalimartha, S.,2008. Atlas Tumbuhan Indonesia. Jilid V. Jakarta : Permata Bunda.

Djajadisastra, J., 2004. Cosmetic Stability. Seminar Setengah Hari HIKI, Departemen Farmasi Fakultas Matematika dan Ilmu Pengetahuan Alam.Depok: Universitas Indonesia.

Elya, B., Dewi, R., Haqqi, M Budiman., 2013. Antioxidant Cream of Solanumlycopersicum L. International Journal of PharmTech Research. West Java, University of Indonesia.

Garg, A., D. Aggarwal, S. Garg, dan A. K. Sigla., 2002. Spreading of Semisolid Formulation. USA: Pharmaceutical Technology

Hasim., Didah, N.F., Dimas, A., Yupi, Y.A., 2019. Ekstrak Etanol Daun Belimbing Wuluh (Averrhoa bilimbi L) Sebagai Antioksidan dan Antiinflamasi. Jurnal Aplikasi Teknologi Pangan. 8(3): 86-93.

Sugiyono, Hernani, Y., dan Mufrod. 2012. Formulasi Salep Ekstrak Air Tokek (Gekko gecko) Untuk Penyembuhan Luka. Media Farmasi Indonesia. 11(2):

Insani, M., Evi, L., Iis, R., 2016. Penggunaan Ekstrak Daun Belimibing Wuluh Terhadap Masa Simpan Filet Patin Berdasarkan Karakteristik Organoleptik. Jurnal Perikanan Kelautan. 6 (2): 14-21.

Ismarani, D., Pratiwi, L., dan Kusharyanti, I. 2014., Formulasi Gel Pacar Air (Impatiens balsamina Linn.) Terhadap Propionibacterium acnes dan Stapylococcus epidermisdis. Pharm Sci Res. 1(1): 30-45.

Meila, O., Athika,P., Jenny, P., Wahyudi, U.H., 2017. Formulasi Krim Ekstrak Etanol Daun Beluntas (Pluchea indica (L.) Less) Dan Uji Kestabilitas Fisiknya. Indonesia Natural Research Pharmaceutical Journal.1 (2): Jakarta.

Parmadi, A. 2016. Uji Efek Tonikum Variasi Dosis Ekstrak Etanol Buah Pare Pada Mencit Jantan (Mus musculus L). Jurnal Kesehatan Samodra Ilmu. 7(1): 10-16.

Putri, V.S., 2013. Formulasi Krim Ekstrak Etanol Herba Pegagan (Centella asiatica (L.) Urban) Konsentrasi 6\% Dan 10\% Dengan Basis Cold Cream Dan Vanishing Cream Serta Uji Aktivitas Antibakteri Terhadap Staphylococcus aureus. Naskah Publikasi. Surakarta : Universitas Muhammadiyah Surakarta.

Rabima, dan Marshali., 2017. Uji Stabilitas Sediaan Krim Antioksidan Ekstrak Etanol 70\% Dari Biji Melinjo (Gnetum gnemon L.). Indonesia Natural Research Pharmaceutical Journal. 2 (1): 107-121.

Rosmala, D., Effionora A., Yunita, K S., 2014. Uji Stabilitas Fisik Formula Krim Yang Mengandung Ekstrak Kacang Kedelai (Glycine max). Pharm Sci Res. 1 (3): 194-208.

Rowe, R.C., Sheskey, P.J. and Quinn M., E. 2009. Handbook of Pharmaceutical Excipients. Fifth Edision. Lexi-Comp: American Pharmaceutical Association.

Ulaen, Selfie P.J., Banne, Yos Suatan dan Ririn A., 2012. Pembuatan Salep Anti Jerawat dari Ekstrak Rimpang Temulawak (Curcuma xanthorrhiza Roxb.). Jurnal Ilmiah Farmasi, 3(2): 45-49.

Faradiba, Faisal, A., dan Ruhama, M. 2013. Formulasi Krim Wajah Dari Sari Buah Jeruk Lemon (Vitis vinifera L.) Dengan Variasi Konsentrasi Emulgator. Majalah Farmasi dan Farmakologi. 17 (1) : $17-20$

Yusriani. 2017. Uji Aktivitas Ekstrak Daun Belimbing Wuluh (Averrhoa bilimbi L.) terhadap Pertumbuhan Staphylococcus aureus dan Propionibacterium acnes. Makassar: Akademi Yamasi Makassar. 